\title{
Bur open Prevalence of respiratory symptoms at two time points in a population of children in Manchester-a cohort study
}

\author{
Mary F Linehan, ${ }^{1}$ Robert M Niven, ${ }^{1}$ David N Baxter, ${ }^{2}$ Julie A Morris, ${ }^{1}$ \\ Timothy L Frank ${ }^{1}$
}

To cite: Linehan MF, Niven RM, Baxter DN, et al. Prevalence of respiratory symptoms at two time points in a population of children in Manchester-a cohort study. BMJ Open 2012;2:e001485. doi:10.1136/bmjopen-2012001485

- Prepublication history and additional material for this paper are available online. To view these files please visit the journal online (http://dx.doi.org/10.1136/ bmjopen-2012-001485).

Received 28 May 2012 Accepted 30 August 2012

This final article is available for use under the terms of the Creative Commons Attribution Non-Commercial 2.0 Licence; see http://bmjopen.bmj.com

${ }^{1}$ Manchester Academic Health Science Centre, University Hospital of South Manchester NHS Foundation Trust, The University of Manchester, Manchester, UK

${ }^{2}$ Manchester Academic Health Science Centre, The

University of Manchester, Manchester, UK

Correspondence to Dr Mary F Linehan; mary. linehan@manchester.ac.uk

\section{ABSTRACT}

Objective: Although the prevalence of asthma and atopy has been noted to have increased in recent decades, patterns of asthma prevalence have, traditionally, been difficult to track. Most reports on trends in childhood asthma have been cross-sectional measuring the prevalence in cohorts of similar aged children at different time points. The aim of this paper is to report on the prevalence of symptoms in the same cohort at two separate time points.

Design: Retrospective cohort study.

Setting: Community-based study, Central Manchester. Participants: MANCAS1, study $n=5086$, participation $\mathrm{n}=2414$. MANCAS2, study $\mathrm{n}=6338$, participation $n=1608$. Children born in a hospital in Manchester within specified dates and still living or attending a school in Central Manchester were eligible for inclusion. Children on an 'at-risk' register or living with short-term carers were excluded.

Outcome measures: Data on respiratory symptoms were collected at two separate time points using parent completed questionnaires.

Results: Response rate for MANCAS1 was $47.5 \%$ and $25.4 \%$ for MANCAS2. There were 801 individuals for whom a response to both studies was received. There was a significant reduction in the prevalence of night cough $(29.5 \%$ vs $18.3 \%$, McNemar $<0.01)$ and antibiotic use for respiratory infections $(9.1 \%$ vs $4.3 \%$, McNemar $<0.01$ ) between the two study time points. The prevalence of hay fever/eczema increased ( $41.6 \%$ vs $46.9 \%$, McNemar $<0.01$ ) between the two studies. There was no significant difference in the prevalence of wheeze, exercise-induced wheeze or asthma medication.

Conclusions: Although this report of respiratory symptom prevalence in the same population at two time points over a 7-year period shows a constant burden of asthma symptoms, there is some suggestion of variability in asthma symptom prevalence within the cohort as the children matured while the burden of allergy symptoms increased.

\section{INTRODUCTION}

The prevalence of asthma and atopy has been noted to have increased in recent

\section{ARTICLE SUMMARY}

Article focus

- Prevalence of respiratory symptoms in the same population of children at two time points-at age 6-11 years and at age 13-17 years.

Key messages

- No overall change in prevalence of wheeze, wheeze with exercise or asthma medication in the cohort between the two study periods.

- Gender differences in wheeze prevalence disappeared between childhood and adolescence.

Strengths and limitations

- Major strength of the study is the inclusion of the same population of children at two separate time points which allows the study to follow the natural course of respiratory symptoms in these children.

- Major limitation is the low response rate which might have exposed the study to response bias.

decades $^{1}$ with reports of a decrease or flattening of the prevalence in more recent times. ${ }^{2}$ However, patterns of asthma prevalence have, traditionally, been difficult to track as different definitions of disease and different methodologies have been used in different age and ethnic groups worldwide. ${ }^{3}$

The International Study of Asthma and Allergies in Childhood (ISAAC) ${ }^{4}$ was designed to measure the prevalence and identify trends in asthma and allergy in children worldwide using standardised methods. ISAAC 1 and 3 studies have now reported on worldwide prevalence and trends in cohorts of similar aged children at different time points. ${ }^{1}$ Most other reports on trends in childhood asthma have also been cross sectional measuring the prevalence in cohorts of similar aged children at different time points. Very few studies have followed the same cohort as they age and measured the prevalence in the same children at two or more time points as was done by Frank et al. ${ }^{5}$ 
MANCAS1 ${ }^{6}$ and MANCAS2 were studies carried out 7 years apart in a cohort of children to investigate differences in the prevalence of asthma and atopy in BCG vaccinated and non-vaccinated children in Manchester. As part of the MANCAS studies data were collected on respiratory symptoms when the cohort was aged between 6 and 11 years and again when they were aged between 13 and 17 years of age. This paper reports on the prevalence of symptoms at two separate time points in those who responded to both studies.

\section{BACKGROUND}

\section{MANCAS1}

MANCAS1 was set up to investigate the theory that the immunomodulating properties of BCG vaccination could reduce the risk of asthma and/or atopy for children given the vaccination as neonates.

St Mary's Hospital in Manchester routinely offers BCG vaccination for all babies born there. In November 1994, after the discovery that 857 infants had accidently been given an overdose of BCG vaccination ${ }^{7}$ the hospital suspended this policy and re-introduced it in October 1996.

This inadvertently presented an ideal opportunity to investigate the relationship between BCG vaccination and atopic diseases as it provided a unique population of children born during a period of time when vaccination policy in the city's main maternity hospital changed twice within a relatively short period of time.

Children born in St Mary's Hospital in Manchester between 1 July 1993 and 31 December 1993 and between 18 November 1994 and 31 March 1997 who were still resident or attending a school in Greater Manchester were eligible for inclusion in MANCAS1. Children born between 1 January 1994 and 17 November 1994 were excluded as they were eligible for vaccination during the period when higher than recommended doses of BCG were administered. Vulnerable children (on an at-risk register) and children living with a short-term carer were also excluded. Eligible children were identified from a primary care trust (PCT) database. Parental agreement to disclose contact details and medical information held by the PCT was sought before release of data to the study team. Ethical approval for the study was obtained from a Manchester Local Research Ethics Committee.

Questionnaires, based on the ISAAC questionnaire, ${ }^{4}$ were posted to the parents/guardians who had not objected to disclosure by the PCT. BCG vaccination status as well as other recommended childhood immunisations was determined from records held by the PCT.

MANCAS1 included 5086 children and there were 2414 responders to the questionnaire, a response rate of $47.5 \%$. Demographic data were available for comparison between responders and non-responders. Responders were likely to be older than non-responders (6.28 vs 6.18 years, $\mathrm{p}=<0.01$ ) and there were significantly more male responders than male non-responders $(53.6 \%$ vs $50.7 \%, \mathrm{p}=0.04)$.
The overall prevalence of wheeze in the past 12 months was $20.3 \%$, and $38.8 \%$ of children were reported to have a history of hay fever or eczema. The prevalence of wheeze was lower for children given neonatal BCG vaccination (OR $0.68,95 \%$ CI 0.53 to 0.87 ).

\section{MANCAS2}

MANCAS2 was designed to follow up these children 7 years later and, because MANCAS1 had identified an association between neonatal BCG vaccination and a lower prevalence of wheeze, children who had been eligible for vaccination when the high-dose BCG was administered were included to investigate if there was a doseresponse relationship. Vulnerable children (on an at-risk register) and children living with a short-term carer were excluded. MANCAS1 had not included a provision for the follow-up study so new ethical approval for the study was obtained from a Manchester Local Research Ethics Committee.

The methodology for MANCAS2 also differed in several other respects. Although eligible children were again identified on the PCT database on this occasion the letter of invitation and the questionnaire were sent in the same communication by the PCT with the explanation that return of the questionnaire constituted consent for release of contact and medical data held by the PCT to the study team.

Although the children in this study were now aged 13-17 years and ISAAC questionnaires for this age group are generally directed to the children themselves, the questionnaire in MANCAS2 was directed to the parents to facilitate comparison with MANCAS1. The questionnaire was similar to that used in MANCAS1 with the addition of questions adapted from the ISAAC rhinitis and eczema questionnaires. ${ }^{4}$ BCG vaccination status, as well as other recommended childhood immunisations, was determined from records held by the PCT.

The study population for MANCA2 consisted of 6338 children. This was larger than that for MANCAS1 due to the addition of children born during the period when high-dose BCG was administered and also because parents were not given the choice to opt out before receipt of a questionnaire. There were 1608 responses, a response rate was $25.4 \%$. Comparisons were not possible between responders and non-responders in MANCAS2 as data for non-responders were not accessible to the study team due to the different methods of obtaining consent to disclose information.

The overall prevalence of wheeze was $15.1 \%$, and $45.1 \%$ of respondents reported a history of hay fever or eczema. No statistically significant differences were noted for respiratory or allergy symptoms between those who did and did not have neonatal BCG vaccination in MANCAS2.

\section{Current study}

This paper reports on the prevalence of the main respiratory outcomes at two time points for those who 
Table 1 Responders to both MANCAS1 and MANCAS2 studies

\begin{tabular}{lllllll}
\hline & $\begin{array}{l}\text { Wheeze in past } \\
\mathbf{1 2} \text { months }\end{array}$ & $\begin{array}{l}\text { Exercise } \\
\text { induced wheeze }\end{array}$ & Night Cough & $\begin{array}{l}\mathbf{2} \text { courses } \\
\text { antibiotics }\end{array}$ & $\begin{array}{l}\text { Asthma } \\
\text { medication }\end{array}$ & $\begin{array}{l}\text { History hay } \\
\text { fever/eczema }\end{array}$ \\
\hline $\begin{array}{l}\text { MANCAS1 } \\
\text { N=801 }\end{array}$ & $17.7 \%(139)$ & $11.7 \%(93)$ & $29.5 \%(231)$ & $9.1 \%(72)$ & $14.8 \%(117)$ & $41.6 \%(322)$ \\
MANCAS2 & $15.7 \%(123)$ & $12.5 \%(99)$ & $18.3 \%(143)$ & $4.3 \%(34)$ & $14.7 \%(116)$ & $46.9 \%(363)$ \\
N=801 & & 8 & 19 & 12 & 12 & 27 \\
Missing data & 16 & 0.60 & $<0.01$ & $<0.01$ & 1.00 & $<0.01$ \\
McNemar test & 0.15 & & & & &
\end{tabular}

responded to both MANCAS studies (MANCAS1\&2). The prevalence is compared between the two time points and the statistical significance of any differences was calculated using the McNemar test.

Differences between those who responded only to MANCAS1 and those who responded to MANCAS1+2 were examined using data from MANCAS1 when the cohort was aged between 6 and 11 years of age.

\section{RESULTS}

There were 801 individuals for whom a response to MANCAS1\&2 was received. The prevalence of the main respiratory outcomes measured in each of the studies for these 801 respondents is shown in table 1. There was no significant difference in the prevalence of wheeze, exercise-induced wheeze or asthma medication. There was a significant reduction in the prevalence of night cough and antibiotic use for respiratory infections between the two time points. The prevalence of hay fever/eczema increased in the cohort between the two studies.

Responders to MANCAS1\&2 were aged 7-11 years when they responded to MANCAS1, $55.4 \%$ were male.
The most common ethnic group was white at $59.6 \%$, followed by Pakistani at $15.9 \%$. The prevalence of wheeze in MANCAS1 for those with data available from MANCAS1\&2 was $17.7 \%$ and $41.6 \%$ had a history of hay fever/eczema.

Responders to MANCAS1 only were aged 6-11 years and $52.8 \%$ were male. The most common ethnic group was white at $56.7 \%$, followed by Pakistani at $15.5 \%$. The prevalence of wheeze was $21.8 \%$, and $37.5 \%$ had a history of hay fever/eczema.

There were statistically significant differences within the age range for those who responded to MANCAS1 only and those who responded to MANCAS1\&2. Responders to MANCAS1\&2 were slightly older. There was no significant difference in gender and, when amalgamated into four broad categories, there were no significant differences in ethnic origin. There were no significant differences for history of hay fever or eczema. The difference in the prevalence of wheeze was statistically significant (table 2 ).

There were gender differences for the prevalence of wheeze in MANCAS1 but not MANCAS2. For responders to MANCAS1 only, the prevalence of wheeze was

Table 2 Characteristics of responders to MANCAS1only and to MANCAS1\&2

\begin{tabular}{|c|c|c|c|}
\hline & Responders MANCAS1 only $\mathrm{N}=1613$ & Responders MANCAS1\&2 N=801 & \\
\hline \multicolumn{4}{|c|}{ AGE when responded to MANCAS1 } \\
\hline 6 years & $0.4 \%(6)$ & $0 \%(0)$ & $\chi_{\text {trend }}^{2}=236.92$ \\
\hline 7 years & $78.4 \%(1264)$ & $45.2 \%(362)$ & $P<0.01$ \\
\hline 8 years & $13.3 \%(214)$ & $32.2 \%(258)$ & \\
\hline 9 years & $7.1 \%(114)$ & $19.5 \%(156)$ & \\
\hline 10 years & $0.9 \%(14)$ & $3.0 \%(24)$ & \\
\hline 11 years & $0.1 \%(1)$ & $0.1 \%(1)$ & \\
\hline Male Gender & $52.8 \%(851)$ & $55.4 \%(444)$ & $\begin{array}{l}\chi_{1}^{2} 1.54 \\
P=0.22\end{array}$ \\
\hline \multicolumn{4}{|l|}{ Ethnic origin } \\
\hline White & $56.7 \%(900)$ & $59.6 \%(468)$ & $\chi_{3}^{2} 3074$ \\
\hline Asian & $20.6 \%(327)$ & $21.1 \%(166)$ & $P=0.29$ \\
\hline Black & $16.2 \%(257)$ & $13.5 \%(106)$ & \\
\hline Other & $6.4 \%(102)$ & $5.7 \%(45)$ & \\
\hline \multicolumn{4}{|l|}{43 missing data } \\
\hline Hay fever/eczema & $37.5 \%(595)$ & $41.2 \%(323)^{\star}$ & $\chi_{1}^{2}=2.96, p=0.09$ \\
\hline Wheeze in past 12 months & $21.8 \%(350)$ & $17.5 \%(140)^{\star}$ & $\chi_{1}^{2}=5.89, p=0.02$ \\
\hline
\end{tabular}

*Slightly different prevalence for wheeze and hayfever/eczema than in table 1 because of slight variations in number of missing data in the analyses. 
$23.7 \%$ for males and $19.1 \%$ for females $\left(\chi_{1}^{2}=3.90\right.$, $\mathrm{p}=0.05)$. For responders to MANCAS1\&2, the prevalence of wheeze for males in MANCAS1 was 20.1\% and for females it was $14.3 \%\left(\chi_{1}^{2}=4.54, \mathrm{p}=0.03\right)$. For responders to MANCAS1\&2, the prevalence of wheeze in MANCAS2 was $17.5 \%$ for males and $13.4 \%$ for females $\left(\chi_{1}^{2}=2.55, \mathrm{p}=0.11\right)$.

\section{DISCUSSION}

This paper details the prevalence of respiratory outcomes in a cohort of children who responded to both phases of the MANCAS study. The response rate for both studies was lower than anticipated, particularly so for MANCAS2. However, a publication from our centre ${ }^{8}$ reports that response to postal questionnaires has been falling in recent years and suggests that survey fatigue and reluctance to reveal personal information as possible reasons. In contrast to MANCAS2 where return of the questionnaire signified consent to participate potential participants in MANCAS1 were sent a letter describing the study and asking parents to return a refusal slip if they did not wish to participate. A study in Sweden ${ }^{9}$ which compared different approaches for consent in postal questionnaire surveys reported a higher response for the approach used in MANCAS1 when compared with the approach used for MANCAS2. The modification in the method of obtaining consent between the two MANCAS studies was necessary in order to comply with research ethics committee guidelines but might account for some of the differences in the response rate between the studies.

Missing data imputation was not considered an appropriate measure for addressing the low response rate as it was not possible to derive an accurate model due to the large amount of missing data.

Because of the low response rates the MANCAS studies are at increased risk of bias if those with respiratory symptoms were more likely to respond than those without such symptoms. The significantly lower prevalence of wheeze in MANCAS2 suggests that this was not the case. Furthermore, a comparison of the prevalence reported in the MANCAS studies with the prevalence reported in other studies of respiratory symptoms in children in the UK does not show an overwhelming preponderance of symptoms in the MANCAS studies, suggesting that responder bias is unlikely to have unduly skewed the prevalence identified in MANCAS. Using a different cohort of children in Manchester, a study carried out in the same centre reported a 12-month prevalence of $22 \%$ for wheeze for children aged up to 16 years in 2001 while the prevalence of night cough was $25 \%$, and $14 \%$ reported using asthma medication in the past 12 months. ${ }^{5}$ An ISAAC written questionnaire study on the Isle of Wight identified $18.9 \%$ prevalence of current wheeze among 10 years olds ${ }^{10}$ and Malik et $a{ }^{11}$ reported a prevalence of wheeze in the past 3 years of $22.2 \%$ for $9-12$ year olds in Aberdeen.
The prevalence in MANCAS2 is derived from parental responses to questions rather than from the participants themselves. Possibly the prevalence for each of the outcomes measured would have been different if the adolescents themselves had completed the questionnaire but parental completion was retained to streamline, as much as possible, the methods employed for both MANCAS studies. A study comparing parental and selfreported responses to an ISAAC asthma questionnaire reveals higher current symptom prevalence reported by the adolescents than by the parents, more particularly so for wheeze after exercise. ${ }^{12}$ If a similar discrepancy occurred in our study then it is possible that significant differences in the prevalence would have been observed between the two studies. However, parents were encouraged to discuss the study with their child and to obtain their child's agreement before participating in the study. This is likely to have increased the possibility of both the child and parent completing the questionnaire together, a factor noted by Braun-Fahrlander et $a l^{12}$ to increase conformity between parental and adolescent response. A more recent study reported no significant differences between parent and adolescent responses to an ISAAC-based asthma questionnaire in a cohort of 13-14 year olds in a longitudinal asthma and allergy study. ${ }^{13}$

Gender differences in the prevalence of wheeze disappeared between the two time points supporting data from other studies that report gender shifts in the prevalence of asthma during puberty with higher prevalence in male children, similar prevalence during puberty and higher female prevalence in adulthood. ${ }^{14-17}$

Despite the gender shift there was no difference in the prevalence between the two time points hinting perhaps at an ever changing pattern of clinical manifestation of respiratory symptoms that cannot be unravelled from point prevalence data. Strachan $e t a l^{17}$ report on a complex and changing pattern of respiratory symptom prevalence in a cohort followed from birth where various patterns of remission and relapse are observed over a 33-year period. At least two-thirds of the children in Strachan's study who wheezed at age 16 years had first wheezed before the age of 5 years. The Tucson Children's Respiratory Study showed that wheezing patterns are established by the age of 6 years and do not change up to age 16 years for children with respiratory symptoms in the preschool years. ${ }^{18}$

In the cohort who responded to both MANCAS studies there was no change in the prevalence of wheeze, wheeze with exercise or use of asthma medication over a 7-year period suggesting that, for this cohort, those who wheezed in early childhood continued to do so in adolescence, although the gender reconciliation indicates a shifting pattern within the cohort.

The significant decrease in antibiotic use for respiratory infection might suggest a decrease in respiratory infections suffered by children as they age or alternatively might indicate a growing reluctance among GPs (prescribers) to use antibiotics as a first-line treatment option. ${ }^{19}$ 
The significant decrease in night cough might signal maturation of the cough reflex pathway ${ }^{20}$ but also corresponds with adult data describing medically driven falls in adult nocturnal symptoms. ${ }^{21} 22$

The increased lifetime prevalence of hay fever/eczema might simply reflect the additional time available for these disorders to manifest in adolescence. Increases in hay fever and eczema in children in recent decades have also been reported in other studies. ${ }^{23} 24$

\section{CONCLUSION}

Although this report of respiratory symptom prevalence in the same population at two time points over a 7 year period shows a constant burden of asthma symptoms there is some suggestion of variability in asthma symptom prevalence within the cohort as the children matured whilst the burden of allergy symptoms increased.

Acknowledgements We would like to thank the parents and children who participated in the MANCAS studies and Central Manchester PCT for their assistance with the recruitment of participants.

Funding Asthma UK and The Moulton Charitable Foundation had no role in study design; in the collection, analysis, and interpretation of data; in the writing of the report; or in the decision to submit the paper for publication.

Contributors TLF conceived the idea for both MANCAS1 and MANCAS2. TLF and RMN developed the study design for MANCAS1. TLF, RMN, DNB and MFL developed the study design for MANCAS2. JM provided statistical support and advice for both studies. All authors made substantial contributions to the analysis and interpretation of the data and to the drafting of this paper. All authors approved the final version of the manuscript.

Competing interest None.

Ethics approval NHS North West 5 REC-Haydock Park.

Provenance and peer review Not commissioned; externally peer reviewed.

Data sharing statement Further data may be available from the corresponding author upon request.

\section{REFERENCES}

1. Asher MI, Montefort S, Bjorksten B, et al. Worldwide time trends in the prevalence of symptoms of asthma, allergic rhinoconjunctivitis, and eczema in childhood: ISAAC Phases One and Three repeat multicountry cross-sectional surveys. Lancet 2006;368:733-43.

2. Asher MI. Recent perspectives on global epidemiology of asthma in childhood. Allergol Immunopathol (Madr) 2010;38:83-7.

3. Burney P. 'Asthma Epidemiology'. In: Seaton A, Seaton D, Leitch AG, eds. Crofton and Douglas's respiratory diseases. Vol. 2, 5th edn. Oxford: Blackwell Science Ltd, 894-905.

4. Asher MI, Keil U, Anderson HR, et al. International Study of Asthma and Allergies in Childhood (ISAAC): rationale and methods. Eur Respir J 1995;8:483-91.
5. Frank PI, Wicks PD, Hazell ML, et al. Temporal change in the prevalence of respiratory symptoms and obstructive airways disease 1993-2001. BJGP 2005;55:596-602.

6. Linehan MF, Frank TL, Hazell ML, et al. Is the prevalence of wheeze in children altered by neonatal BCG vaccination? JACI 2007:119:1079-85.

7. Puliyel JM, Hughes A, Chiswick ML, et al. Adverse local reactions from accidental BCG overdose in infants. $B M J$ 1996;313:528-9.

8. Hazell ML, Morris JA, Linehan MF, et al. Factors influencing response to postal questionnaire surveys about respiratory symptoms. Prim Care Respir J 2009;18:165-70.

9. Stenhammar C, Bokström P, Edlund B, et al. Using different approaches to conducting postal questionnaires affected response rates and cost efficiency. J Clin Epidemiol 2011;64:1137-43.

10. Kurukulaaratchy RJ, Fenn M, Twiselton R, et al. The prevalence of asthma and wheezing illnesses amongst 10-year-old schoolchildren. Respir Med 2002;96:163-9.

11. Malik G, Tagiyeve N, Aucott $\mathrm{L}$, et al. Changing trends in asthma in 9-12-year-olds between 1964 and 2009. Arch Dis Child 2011;96:227-31.

12. Braun-Fahrländer Ch, Gassner M, Grize L, et al. Comparison of Responses to an Asthma Symptom Questionnaire (ISAAC Core Questions) Completed by Adolescents and Their Parents. Pediatr Pulmonology 1998;25:159-66.

13. Hedman L, Lindgren $B$, Perzanowski M, et al. Agreement between parental and self completed questionnaires about asthma in teenagers. Pediatr Allergy Immunol 2005;16:176-81.

14. Vink NM, Postma DS, Schouten JP, et al. Gender differences in asthma development and remission during transition through puberty: The Tracking Adolescents' Individual Lives Survey (TRAILS) study. J Allergy Clin Immunol 2010;126:498-504.

15. Almqvist $\mathrm{C}$, Worm $\mathrm{M}$, Leynaert $\mathrm{B}$. Impact of gender on asthma in childhood and adolescence: a GA ${ }^{2}$ LEN review. Allergy 2007:63:47-57.

16. Postma DS. Gender differences in asthma development and progression. Gender Medicine 2007;4(Suppl B):S133-46.

17. Strachan DP, Butland BK, Anderson HR. Incidence and prognosis of asthma and wheezing illness from early childhood to age 33 in a national British cohort. BMJ 1996;312:1195-99.

18. Morgan WJ, Stern DA, Sherrill DL, et al. Outcome of Asthma and Wheezing in the First 6 years of Life: Follow up through Adolescence. Am J Respir Crit Care Med 2005;172:1253-8.

19. Gulliford M, Latinovic R, Charlton J, et al. Selective decrease in consultations and antibiotic prescribing for acute respiratory tract infections in UK primary care up to 2006. $J$ Public Health 2009;31:512-20.

20. Varechova S, Plevkova J, Hanacek J, et al. Role of gender and pubertal stage on cough sensitivity in childhood and adolescence. J Physiol Pharmacol 2008;59:719-26.

21. Lockey RF, DuBuske LM, Friedman B, et al. Nocturnal asthma: effect of salmeterol on quality of life and clinical outcomes. Chest 1999;11593:666-73.

22. Pearlman D, Nathan R, Meltzer E, et al. Effect of mometasone furoate/formoterol combination therapy on nocturnal awakenings in subjects with persistent asthma. Allergy Asthma Clin Immunol 2011;7(suppl 2):A14

23. McNeill G, Tagiyeva $\mathrm{L}$, Aucott $\mathrm{L}$, et al. Changes in the prevalence of asthma, eczema and hay fever in pre-pubertal children a 40 year perspective. Paediatr Perinat Epidemiol 2009; 23:506-12.

24. Gupta R, Sheikh A, Strachan DP, et al. Time trends in allergic disorders in the UK. Thorax 2007;62:91-6. 